\title{
Introduction: Black Swans and Sinatra Inferences
}

When, on 14 August 2018, the Morandi Bridge in Genoa, Italy, collapsed, it killed 43 people and made some 600 homeless whose dwellings were crushed by the impact of the debris. Obviously, a bridge does not collapse just out of the blue. In the case of the Morandi bridge, "investigations indicated poor design, questionable building practices, and insufficient maintenance - or a combination of these factors-as a possible cause of the collapse." Whatever the individual reasons in an individual case-the basic fact is that the collapse of bridges and buildings remains a highly unlikely event. After all, building under public oversight and control is one of the oldest collective activity of humankind. The practical purpose of building would be pointless without adequate safety, and the concern for safety emerged not only into professional standards of architects, engineers and public officials but also in the existence of governmental agencies supervising construction in accordance with relevant regulation. To that extent, collapsing bridges and buildings represent a Black Swan phenomenon ${ }^{2}$ - one whose irregularity and rareness make it hard to predict but whose high impact requires knowledge-based prevention. The puzzle is that the dramatic consequences of failing bridges and buildings imply a

\footnotetext{
${ }^{1}$ Massimiliano Burlando et al.: Investigation of the Weather Conditions During the Collapse of the Morandi Bridge in Genoa on 14 August 2018 Using Field Observations and WRF Model. Atmosphere 11 (2020): 724.

${ }^{2}$ Nicholas Nassim Taleb: The Black Swan: The Impact of the Highly Improbable.
} New York: Random House 2007.

W. Seibel, Collapsing Structures and Public Mismanagement, https://doi.org/10.1007/978-3-030-67818-0_1 
quest for solid and generalizable knowledge while the irregularity and rareness of such failure seriously limits the basis of generalization.

It is here where this book sets its focus. It analyzes four spectacular cases of collapsing structures, two bridges and two buildings: The West Gate Bridge in Melbourne that collapsed on 15 October 1970 when still under construction, the I-35W Mississippi River bridge in Minneapolis that collapsed on 1 August 2007, the Canterbury Television (CTV) Building in Christchurch that collapsed on 22 February 2011 after an earthquake and the Ice Skating Rink in the Bavarian city Bad Reichenhall whose roof collapsed on 2 January 2007. What made these accidents true disasters was the loss of human lives. Thirty-five people were killed in the collapse of the West Gate Bridge, 13 people died in the I-35W disaster. Even more dramatic was the death toll claimed by the collapse of the CTV building in Christchurch where 115 were killed, many of them international students of a language school located in the multi-story building. The collapse of the ice-skating rink roof in Bad Reichenhall claimed the lives of 15 people, among them 12 children skating in the arena during New Year's vacation.

What these cases have in common in the pragmatic perspective of research is that they are well documented, either through reports of investigation committees or judicial proceedings. While, accordingly, the empirical basis for causal analyses is solid, the question of representativeness and generalization remains valid in more than one sense. Does what applies to the conditions of failure in Australia, New Zealand, the USA and Germany also apply to conditions in China, Bangladesh or Nigeria? Moreover, how can we generalize from just four cases or "observations" anyway?

\subsection{Rare Incidences and the Quest For InFERENCE AND LEARNING}

Civil engineers will take it for granted that each individual case of collapsing bridges and buildings, however rare and unique, entails instructive lessons for the construction and building community around the world. It is always about a particular type of bridge, a particular type and composition of material and particular proceedings in the course of construction. So there are structures and processes that are unique and exemplary-thus generalizable - at the same time. Which applies to every single case analyzed in this book, whether it was the wrong choice of glue for a wooden roof structure, poorly designed gusset plates connecting steel truss members or insufficiently stabilized diaphragms connecting the floors of a 
building to supporting beams. What sounds uncommon and incomprehensible for laypeople is easy to understand for the expert. Moreover, the expert will also spontaneously generalize. He or she knows about the peculiarities of particular structural designs, their strengths and weaknesses, their advantages and disadvantages because those peculiarities are systemic in nature. Gusset plates stabilizing the nodes of a steel truss are a common phenomenon, every wooden roof structure needs water-resistant glue and everywhere the stability of bridges and buildings relies on diaphragms connecting the various parts of their primary structure. Accordingly, generalization from a single case of failure is not only possible but imperative when it comes to serious issues of stability and safety.

By contrast, the non-technical causes of failure are, at first glance, nongeneralizable. Why and under what circumstances existing regulation and professional standards remain unobserved, why contractors and consultants are unable to coordinate their action or why local building authorities do not enforce the relevant safety regulation seems to be contingent and unpredictable. In reality, however, the non-technical causes of failure share the characteristics of their technical counterparts. They too are systemic in nature. Public authorities have their own structural and agencyrelated risk zones. This applies to information asymmetries in a hierarchical setting known as principal-agent-problem, ${ }^{3}$ unresolved problems of coordination, ${ }^{4}$ goal displacement in the sense that standard operating procedures and routines become an end in themselves, ${ }^{5}$ the "normalization of deviance" in the form of counterproductive routines become engrained and thus are taken for granted in an organization's everyday life, 6 "bureaucratic politics" and inter-agency rivalry that makes public authorities more concerned with themselves than with the concerns of their clientele ${ }^{7}$ or the

\footnotetext{
${ }^{3}$ Sanford J. Grossman and Oliver D. Hart: An Analysis of the Principal-Agent Problem. Econometrica 51 (1983): 7-45.

${ }^{4}$ James D. Thompson: Organizations in Action: Social Science Bases of Administrative Theory. New York: McGraw-Hill 1967.

${ }^{5}$ Robert K. Merton: Bureaucratic Structure and Personality. Social Forces XVII (1940): $560-568$.

${ }^{6}$ Diane Vaughan: The Dark Side of Organizations: Mistake, Misconduct, and Disaster. Annual Review of Sociology 25 (1999): 271-305; Vaughan, Diane: The Challenger Launch Decision: Risky Technology, Culture and Deviance at NASA. 2nd ed., Chicago and London: The University of Chicago Press 2016.

${ }^{7}$ For the phenomenon of "bureaucratic politics" cf. Graham T. Allison and Morton H. Halperin: Bureaucratic Politics. A Paradigm and Some Policy Implications. World Politics 24 (1972): 40-79.
} 
proverbial red tape in the sense of over-regulation that undermines the compliance of both staff members of public authorities and their clientele. ${ }^{8}$

However, precisely because these pathologies are 'standard errors' they are usually kept under control in a properly managed organization and, accordingly, properly managed public authorities as well. This, in turn, leaves us with an ambivalent diagnosis. It is not particularly convincing to assume the failure of public bureaucracies to exercise proper and effective control over building and construction to result from well-known deficiencies. After all, the hazards involved are not only known but subject to strict regulation. Division of labor between building authorities, contractors and consultants is inevitable, yet at the same time entirely manageable as long as fault lines and potential loss of information is soberly recognized as a risk factor and neutralized accordingly. By the same token, a conflict of interest exists between contractors and consultants vis-à-vis public building authorities when it comes to the desire for expeditious processing of applications for building permits and the indispensable diligence of reviewing and recalculating the structural design of bridges and buildings. Yet, public building authorities are usually robust and experienced enough to resist a pressure to accelerate the review of applications for building permits at the expense of professional diligence. Finally, there might be a 'horizontal' power asymmetry among the clientele of building authorities. It makes a difference whether the applicant for a building permit is a future homeowner or a contractor running a large-scale building project that one way or the other is also important for urban development. But even this is not uncommon and, accordingly, it is virtually unlikely that local authorities when dealing with consultants and contractors of major construction projects make concessions at the expense of compliance with safety regulation. Rather, there is good reason in acknowledging that, when it comes to human safety, a zero tolerance principle shapes the mindset of regulators, public officials and professionals of the architecture and engineering community.

This implies that, for the sake of ontological realism and methodological parsimony, the causal analysis of the non-technical origins of disasters in the realm of building and construction can be focused more narrowly. The question is, specifically, what counterincentives make human actors neglect or suspend the very professional and institutional routines that usually neutralize the impact of standard pathologies of formal organizations under the condition of risks for human life and limb. Which also is

\footnotetext{
${ }^{8}$ Alvin W. Gouldner: Patterns of Industrial Bureaucracy. New York: The Free Press 1954.
} 
the key to generalization. It should be possible to identify typical mechanisms that make public officials, architects and engineers neglect their professional standards and/or existing regulation. Consequently, those mechanisms can also be defined as risk factors in their own right since they are powerful enough to cause failure in the restrictive environment of otherwise sound accountability structures, incorruptible bureaucracy and high professional standards of public officials, architects and engineers. Accordingly, those mechanisms can be assumed to be even more powerful - thus detrimental - under less restrictive conditions. Which is known as the "Sinatra Inference": If a causal mechanism is strong enough "to make it" under restrictive conditions-i.e., when causal leverage is supposed to be low-it is likely to have even more of an impact under less restrictive conditions. ${ }^{9}$ For instance, when and where accountability structures are weaker, professional standards lower, public bureaucracies more corruptible and, last but not least, when and where less vital issues are at stake than the protection of human life and limb.

\subsection{Causal Process Tracing: Turning Points and Critical Junctures, Necessary and Sufficient Conditions, and Contributing Factors}

Detecting the counterincentives that make human actors neglect or suspend professional and institutional routines that usually neutralize the impact of standard pathologies of formal organizations requires causal process tracing. ${ }^{10}$ Unlike the conventional causal analytic technique of defining independent variables and testing hypotheses referring to the impact on a predefined dependent variable, process tracing has the potential of detecting causal mechanisms rather than just causal effects expressed through correlation or regression coefficients. This, in turn, not only requires a careful and fine-grained longitudinal analysis of relevant events

\footnotetext{
${ }^{9}$ Referring to Frank Sinatra's "New York, New York" song with the key phrase, "if I can make it there, I'll make it anywhere". Cf. Jack S. Levy: Case studies. Type, designs, and logics of inference. Conflict Management and Peace Science 25 (2008): 1-18 (12).

${ }^{10}$ Out of the burgeoning literature on causal process tracing cf. Derek Beach and Rasmus Brun Pedersen: Process-Tracing Methods: Foundations and Guidelines. 2nd ed., Ann Arbor: University of Michigan Press 2019; Andrew Bennett and Jeffrey T. Checkel: Process Tracing. From Metaphor to Analytic Tool. Cambridge: Cambridge University Press 2015; Nicholas Weller and Jeb Barnes: Finding pathways: Mixed-method research for studying causal mechanisms. Cambridge: Cambridge University Press 2014.
} 
and decisions but also a definition of turning points and critical junctures at which the mechanisms became relevant in shaping the causal process. ${ }^{11}$ Turning points and critical junctures not only mark the points in a timeline at which causal mechanisms are activate but also the situational setting in which necessary and sufficient conditions of the ultimate disaster were fulfilled. The definition of necessary and conditions is complementary to the differentiation of turning points and critical junctures. A factor or "condition" without which the consequence in question could not have occurred marks a turning point in the sense that from that point on the outcome was likely to occur but not yet inevitable. A causal factor, on the other hand, that would have triggered the outcome under any circumstances marks a critical juncture in the sense that from that point on the outcome was virtually inescapable. The occurrence of a single sufficient condition is rare while several necessary conditions may be jointly sufficient for the outcome in question to occur. ${ }^{12}$

There is a gray zone, however, beyond necessary and sufficient conditions that may be termed "contributing factors". ${ }^{13}$ Contributing factors are similar to what in criminology is known as "permissive environment" or "permissive conditions", ${ }^{14}$ i.e. factors that work in favor of particular (undesirable) actions but still leave considerable discretionary leeway for personal decisions. Indirectly, the notion of contributing factors/permissive conditions refers to one distinct difference between the analytical and the normative dimension of causal process tracing. Analytically, the purpose of process tracing is the reconstruction of the causal chain with rigor and accuracy. That accuracy just reflects the deterministic logic of causality whose actual shape and occurrence needs to be analytically reconstructed. By contrast, normative conclusions address risk factors and are, thus, probabilistic in nature. Factors that contribute or just may contribute to an undesirable outcome are a risk factor in their own right and therefore need to be

\footnotetext{
${ }^{11}$ Giovanni Capoccia and Daniel R. Kelemen: The Study of Critical Junctures. Theory, Narrative, and Counterfactuals in Historical Institutionalism. World Politics 59 (2007), 341-369; Gary Goertz and Jack S. Levy: Causal Explanation, Necessary Conditions, and Case Studies. In Gary Goertz and Jack S. Levy (eds.): Explaining War and Peace. Case Studies and Necessary Condition Counterfactuals, London 2007: 9-45 (29-31); David Hillel Soifer: The Causal Logic of Critical Junctures. Comparative Political Studies 45 (2012): 1572-1597. The distinction between turning points and critical junctures is emphasized by Goertz and Levy.

${ }^{12}$ Goertz and Levy: Causal Explanation, Necessary Conditions, and Case Studies, 24-26.

${ }^{13}$ Ibid., 10.

${ }^{14}$ Soifer: The Causal Logic of Critical Junctures.
} 
addressed as such, which in real life means to eliminate them or at least to restrain their detrimental effects. It is not necessary, for instance, to assess with rigor and accuracy the exact impact of speeding and reckless driving in order to define speeding as a risk factor that should be eliminated anyway.

In this very sense, the case analyses presented in this book serve a double purpose. On the one hand, they reassess actual causalities. On the other hand, they identify general structural risk zones and risk increasing behavioral patterns. This is done on the basis of three components, namely an analytical narrative that addresses turning points and critical junctures at which crucial actions or omissions occurred; the definition of necessary and sufficient conditions and 'contributing factors'; the identification of typical causal mechanisms with the potential of generalization.

\subsection{Causal Mechanisms, Near Miss Scenarios, And Points of Intervention}

The analytical narrative addressing turning points and critical junctures as well as various types of causal conditions is inductive in nature. It requires the reassessment of actual processes so that formative actors and decisions become gradually identifiable. By contrast, the definition of generalizable causal mechanisms requires theory-based deduction. The mechanisms themselves are not "visible", they only can be conjectured. ${ }^{15}$ The diagnosis of coordination problems, loss of information, persisting misperceptions etc. remains a matter of theoretical interpretation the basis of which are ontological premises concerning the "system" at hand. ${ }^{16}$ We expect social mechanism in social systems or bio-chemical mechanisms in ecological systems, etc. Which implies that the range of actually relevant mechanisms that shape individual or collective behavior is limited according to the nature of the system itself. Relevant mechanisms on a commodity market, for instance, are demand, supply and competition. There might be further mechanisms like networking in a supply chain or brand reputation but they are of no or limited relevance for the core mechanisms of a market. Similar with authority connected to formal hierarchy or bargaining as the driving mechanism of negotiations.

\footnotetext{
${ }^{15}$ Mario Bunge: Mechanism and Explanation. Philosophy of the Social Sciences 27 (1997): 429-436; Mario Bunge: How Does It Work? The Search for Explanatory Mechanisms. Philosophy of the social sciences 34 (2004): 182-210.

${ }^{16}$ Bunge: Mechanism and Explanation; Bunge: How Does It Work? The Search for Explanatory Mechanisms.
} 
Yet, to what extent human action and interaction is being aggregated to the outcome in question remains to be assessed on a case-by-case basis. Insufficient control and oversight over maintenance of public infrastructure, a bridge for example, may or may not be conducive to poor maintenance itself. And even when maintenance is indeed poor this does not inevitably result in a loss of stability and safety of the bridge. Poor maintenance is certainly a core mechanism which, however, is embedded in permissive conditions and connected to additional factors that may or may not trigger a disastrous outcome. One may thus assume a triplet of mechanisms according to the one introduced by Richard Swedberg ${ }^{17}$ and Peter Hedström and further developed by Hedström and Petri Ylikoski in "Causal mechanisms and the social sciences". ${ }^{18}$ These authors distinguish action-formation, situational and transformational mechanisms (Fig. 1.1).

This differentiated concept of causal mechanisms is, on the one hand, a more elaborate version of actor-centered methodological individualism, represented by "action formation mechanisms" known from James S. Coleman's bathtub metaphor. ${ }^{19}$ On the other hand, the Hedström and Ylikoski concept of causal mechanisms also makes salient that, in principle, not only various types of causal mechanisms are linked to each other but that the "links" signify potential points of intervention. One of those points is located at the interface between situational mechanisms and action formation mechanisms and one at the threshold between action formation mechanisms and the actual occurrence of the outcome.

What one may reasonably assume is that a large amount of the risk potential of situational mechanism is neutralized already at the interface between situational and action formation mechanisms. Which is exactly what regulation of risk prone systems does that emerged in a historically protracted process of learning, decisively accelerated by the industrial

\footnotetext{
${ }^{17}$ Peter Hedström and Richard Swedberg: Social Mechanisms. An Introductory Essay. In Peter Hedström and Richard Swedberg (eds.): Social Mechanisms. An Analytical Approach to Social Theory. Cambridge: Cambridge University Press 1998, 3-32.

${ }^{18}$ Peter Hedström and Petri Ylikoski: Causal mechanisms in the Social Sciences. Annual Review of Sociology 36 (2010): 49-67 (59).

${ }^{19}$ James S. Coleman: Foundations of Social Theory. Cambridge (Mass.): Harvard University Press 1990, 10. The wording "bathtub" does not actually appear in Coleman's book but it has become popular due to the shape of the graph on that very page in support of the claim that the analysis of both social structure and social action has to conceptualize the linkage between the "micro"-level of human action and the "macro"-level of aggregate effects. Hedström and Swedberg, in their 1998 book chapter, referred to the "bathtub" and gave it a more nuanced characteristic while maintaining its basic shape.
} 
Start of Causal Process Macro-level Association

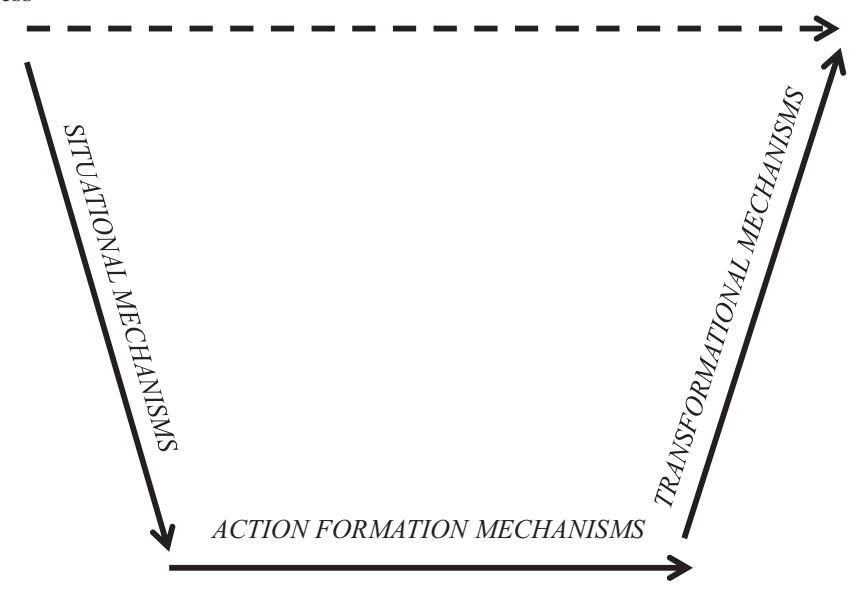

Fig. 1.1 Typology of Causal Mechanisms (adapted from Peter Hedström and Petri Ylikoski: Causal Mechanisms in the Social Sciences. Annual Review of Sociology 36 (2010): 49-67 (59))

revolution since the early 19th century. Still, those precautions might be too weak, they might not be enforced, they might be ignored or deliberately circumvented. At any rate, theses weaknesses pertain to the level of action formation mechanisms.

But even if they do occur those weaknesses and risk increasing behavioral patterns do not necessarily trigger undesirable outcomes. A municipal building authority may be tempted to accelerate the issuance of a building permit in an effort to do justice to the legitimate interest of the applicant and, maybe, the local business community at the expense of diligence in checking structural design issues. That impulse might be the consequence of situational mechanisms in the form of local pressure group influence. Yet, that impulse may be neutralized by senior officials so that the threshold between action formation mechanisms and transformational mechanisms remains intact.

This refers to the general phenomenon of a near miss or close call situation aptly described by Scott Sagan in his seminal book The Limits of Safety of 1993. ${ }^{20}$ Many "accidents" do not happen because of last moment

\footnotetext{
${ }^{20}$ Scott D. Sagan: The Limits of Safety: Organizations, Accidents, and Nuclear Weapons. Princeton, N.J.: Princeton University Press 1993.
} 
interventions as Sagan described for cases of nuclear weapons storage and transport and the failure of strategic missile early warning systems. There is no equivalent analysis pertaining to the construction industry but it is beyond reasonable doubt that in that risk prone environment serious consequences of neglect or outright blunder are frequently being prevented by resolute intervention at a very late stage. What the cases analyzed in this book have in common is that those 'last moment' opportunities existed and, yet, were missed.

\section{4 'Normal Accidents' and Lack of Mindfulness}

The differentiated concept of causal mechanisms is helpful for both explanatory and normative purposes when combined with two prominent concepts of disaster analysis and prevention, namely Normal Accident Theory (NAT) and High Reliability Theory (HRT). Normal Accident Theor $\mathrm{y}^{21}$ became prominent as the first contribution of organization theory to disaster research. What Charles Perrow in his trailblazing book of 1984 stated was that a particular type of organizational structure is toxic. ${ }^{22}$ Organizations that combine tight coupling of sub-units and complex interaction among those units face an unsolvable dilemma, Perrow argued. Complex interaction requires decentralization since coordination under such circumstances requires constant exchange of ideas and deliberation which cannot be organized on the basis of hierarchical control. Centralization and hierarchical control is, however, exactly what keeps tightly coupled organizational systems viable (the railway system is a typical example). Since decentralization and centralization are mutually exclusive organizations that combine complex interaction with tight coupling are not viable either, Perrow stated. They may survive for a while but only as a particularly risk prone structure.

Scott Sagan, in his book on "Organizations, Accidents and Nuclear Weapons" obviously had more than one reason to take Perrow's perspective seriously and yet went one step further when addressing the very question why, despite the undeniable risks aptly characterized by Perrow, risk prone organization structures dealing with particularly dangerous tasks do not constantly create disasters. Which led to an important contribution to what became known as High Reliability Organization Theory or

\footnotetext{
${ }^{21}$ Charles Perrow: Normal Accidents: Living with High Risk Technologies. New York: Basic Books 1984.

${ }^{22}$ Ibid. See also Perrow: Complex Organizations. A Critical Essay. 3rd ed., New York: Random House 1986, 119-156.
} 
just High Reliability Theory (HRT): ${ }^{23}$ Human agency is, after all, a key factor of mitigation and control in a high risk environment of any kind. This is why, Sagan stated, catastrophic accidents with nuclear weapons had not really happened, so far. However, they definitely could have happened and Sagan pointed to incidents at which a disaster had been averted only by a hair's breadth as nuclear 'close calls'.

The very combination of Normal Accident Theory and High Reliability Theory is used in the case analyses of this book in an 'enriched' version that integrates the differentiated concept of causal mechanisms developed by Swedberg, Hedström and Ylikoski. ${ }^{24}$ It is quite in the vein of Normal Accident Theory that particular "structures"-for instance organizational and contractual arrangements-can be identified as particularly risk prone and, yet, not unmanageable. After all, one might assume, in accordance with High Reliability Theory, that the interface between situational mechanisms and action formation mechanisms can be stabilized through mindful control and that the threshold between risk increasing action formation mechanisms and transformational mechanisms can be raised sufficiently in order to prevent a disaster from being triggered. By the same token, however, both 'filters' may be perforated. Which is the logic characterized by the Swiss Cheese metaphor widely in use since its introduction by James T. Reason in the $1990 \mathrm{~s}^{25}$ to disaster research. ${ }^{26}$ The case analyses of this book make the "slices" identifiable as missed opportunities of intervention that could have neutralized the risk increasing effects of situational

${ }^{23}$ Emery Roe and Paul R. Schulman: High Reliability Management: Operating on the Edge. Stanford: Stanford Business Books 2008; Karl E. Weick and Kathleen M. Sutcliffe: Managing the Unexpected. Resilient Performance in an Age of Uncertainty. 2nd ed., Hoboken: John Wiley \& Sons 2007.

${ }^{24}$ The mutual complementarity and cross-fertilization potential of NAT and HRT has been addressed repeatedly in the relevant literature. Cf. Sagan in his 1993 book as well as Shrivastava, Sonpar and Pazzaglia in their article "Normal accident theory versus high reliability theory: A resolution and call for an open systems view of accidents" (Human Relations 62 [2009], 1357-90). None of related contributions refers to causal mechanism analyses though.

${ }^{25}$ Starting with James T. Reason: The Contribution of Latent Human Failures to the Breakdown of Complex Systems. Philosophical Transactions of the Royal Society of London B Biological Sciences 327 (1990): 475-484, and elaborated in James T. Reason: A Systems Approach to Organizational Error. Ergonomics 38 (1995): 1708-1721. See also James T. Reason: Managing the Risks of Organizational Accidents. Farnham: Ashgate Publishing 1997.

${ }^{26}$ Justin Larouzeea and Jean-Christophe Le Coze: Good and bad reasons: The Swiss cheese model and its critics. Safety Science 126 (2020), 1-11. 
mechanisms and/or made the threshold between action formation mechanisms and transformational mechanisms impenetrable.

The collapse of the West Gate Bridge in Melbourne in 1970 was essentially the consequence of a mismatch between an innovative and ambitious structural design and unusual building practice and sub-standard management tolerated by the responsible authority. The failure of the I- $35 \mathrm{~W}$ bridge in Minneapolis in 2006 resulted from the Minnesota Department of Transportation's unwillingness to finance costly structural analyses of the bridge's steel truss. The collapse of the CTV building in Christchurch in 2011 reflects the creeping erosion of professional integrity on the part of a local building authority while the failure of the ice skating rink in Bad Reichenhall whose roof collapsed in early 2006 illustrates the consequences of politicization of the non-politicizable which is human safety. While both the technical and the non-technical risk zones were identifiable for the key actors involved the risks themselves were not neutralized through human intervention. Why not is the very subject of the subsequent case studies.

Open Access This chapter is licensed under the terms of the Creative Commons Attribution 4.0 International License (http://creativecommons.org/licenses/ by $/ 4.0 /$ ), which permits use, sharing, adaptation, distribution and reproduction in any medium or format, as long as you give appropriate credit to the original author(s) and the source, provide a link to the Creative Commons licence and indicate if changes were made.

The images or other third party material in this chapter are included in the chapter's Creative Commons licence, unless indicated otherwise in a credit line to the material. If material is not included in the chapter's Creative Commons licence and your intended use is not permitted by statutory regulation or exceeds the permitted use, you will need to obtain permission directly from the copyright holder.

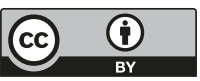

